\title{
ORIENTAÇõES DA UNESCO PARA AS POLÍTICAS PÚBLICAS BRASILEIRAS NA PROTEÇÃO AO DIREITO À INFÂNCIA E À ADOLESCÊNCIA NA DÉCADA DA EDUCAÇÃO (1997-2007)
}

\section{Orientations of the Unesco for the Brazilian public policies on the protection of the right to infancy and to adolescence in the decade of education (1997-2007)}

\section{Orientaciónes de la Unesco para las políticas públicas brasileñas en la protección al derecho a la infancia y la adolescencia en la década de la educación (1997-2007)}

\author{
Caroline Mari de Oliveira ${ }^{1}$ \\ Maria Aparecida Cecílio²
}

RESUMO

\begin{abstract}
O presente texto resulta da investigação acerca dos objetivos e orientações da Organização das Nações Unidas para a Educação, a Ciência e a Cultura (Unesco), publicados na década da educação, 1997-2007, para a proteção do direito à infância e à adolescência. Nosso objeto é o papel da Unesco como agência de intervenção internacional nas políticas educacionais no Brasil na garantia da proteção ao direito à infância e à adolescência. $\mathrm{O}$ objetivo do estudo foi analisar a profusão de valores oferecidos por meio de programas e documentos. No Brasil existem ações na orientação legal que pretendem, principalmente, agir sobre dificuldades de a população viver plenamente os seus direitos. Enfrentam, no fim do século XX e início do século XXI, a prática cruel do trabalho infantil, o qual é tema discutido no mundo inteiro pelas agências internacionais vinculadas à Organização das Nações Unidas (ONU). Nosso estudo vem ratificar que o trabalho infantil e/ou precoce, independentemente dessas ações, foi $e$ tem sido historicamente formador de diversos tipos de crianças, trazendo graves consequências para o desenvolvimento humano. O processo de desenvolvimento humano é roubado no processo de exploração do trabalho infantil. No entanto, para essa parte da população, o trabalho tem roubado a infância, o tempo de aprendizado, o convívio familiar e o descanso, além de trazer consequências como a evasão escolar, o analfabetismo e a repetência.
\end{abstract}

Palavras-chave: direitos do cidadão; políticas públicas; Unesco; trabalho infantil.

\begin{abstract}
This text results from the investigation of objectives and orientations of the Unesco published in the decade of education, 1997-2007, about the protection of the right to infancy. Our goal, the intervention of international agencies on the educational policies and the United Nations for the Education, Science and Culture, the guidelines of the Brazilian policies on the protection of the right of infancy and adolescence, aiming the profusion of values offered by these organizations through programs and documents. In Brazil, there are several projects for legal orientation whose goal is, mainly, to act upon total difficulties of actually profiting from their rights. They have faced, in the end of the XX century and in the beginning of the XXI century, the mean practice of infant work, which has been a topic discussed worldwide by international agencies
\end{abstract}

\footnotetext{
1 Graduanda do curso de Pedagogia da Universidade Estadual de Maringá (UEM). E-mail: oliveiracaroline29@gmail.com, Telefone (44) 9855-3591, Endereço: Rua Seringueiras, 334 - Parque das Bandeiras, Maringá, PR.

2 Doutora e professora adjunto da Universidade Estadual de Maringá (UEM), Departamento de Teoria e Prática da Educação - DTP. E-mail: maacecilio@hotmail.com, Telefone (44) 9813-1617, Endereço: Rua Rio Ligeiro, 849 - Parque Residencial Tuiuti, Maringá, PR.
} 
linked to the United Nations (UN). Our study ratifies that child and/or early labor, independently of these actions, has been historically a trainer of various types of children, causing bad consequences for the human development. Their regular growing process is taken from them in the exploitation of child labor. However, for this part of the population, the work has been stealing their childhood, time of learning, family living and the rest, besides bringing consequences such as school dropout, illiteracy and repetition.

Keywords: Unesco; public policies; rights of the citizen; child labor.

\section{RESUMEN}

En este documento se muestran los resultados de las investigaciones sobre los objetivos y directrices de la Organización de las Naciones Unidas para la Educación, la Ciencia y la Cultura, Unesco, publicado en la década de la educación, 1997-2007, para la protección de los derechos de la infancia y la adolescencia. Nuestro objeto, es el papel de la Unesco como la agencia internacional de intervención en las políticas educacionales en el Brasil, en la garantía de la protección al derecho a la infancia y la adolescencia. El objetivo del estudio fue examinar la profusión de valores ofrecidos por medio de programas y documentos. En Brasil existen acciones en la orientación legal que visa, sobre todo, actuar sobre las dificultades que tiene la población de vivir plenamente sus derechos. Enfrentaron al final del siglo XX y al comienzo del siglo XXI, la cruel práctica del trabajo infantil, lo cual es tema que se discute en el mundo entero por los organismos internacionales vinculados a las Organizaciones de las Naciones Unidas, ONU. Nuestro estudio es el de ratificar el trabajo infantil y / o precoz, independientemente de estas acciones, fue y ha sido históricamente los formadores de los diversos tipos de niños, trayendo graves consecuencias para el desarrollo humano. El proceso de desarrollo humano se roba en el proceso de explotación del trabajo infantil. Sin embargo, para esa parte de la población, el trabajo ha robado la infancia, el tiempo de aprendizaje, la reunión familiar y el descanso, además de traer consecuencias como la deserción escolar, analfabetismo y repitencia.

Palabras clave: derechos del ciudadano; políticas públicas; la Unesco; el trabajo infantil.

\section{Introdução}

O bem-estar social está previsto e garantido em leis importantes, como a Constituição Federal de 1988 e, para a educação, a Lei de Diretrizes e Bases (LDB 9394/96). No entanto, essas leis estão sendo descumpridas e não as vemos na extensão de todo o território brasileiro e para toda a população. Em países neoliberalistas como o Brasil, a questão econômica é bastante relevante. Em nossa realidade, sofremos os ajustes econômicos e políticos que o país necessita realizar interferindo diretamente ou indiretamente no cotidiano das pessoas. As agências internacionais atuam como fiscalizadoras das políticas de Estado, principalmente as educacionais. Elas traçam estratégias e programas que paulatinamente interferem nas decisões educacionais. Contudo, o Estado brasileiro, pressionado por essas agências para mostrar suas estatísticas educacionais e sociais, não se compromete com a priorização da melhoria do desempenho educacional, mas se compromete em mostrar resultados quantitativos, eliminando a qualidade, que é um direito de todo cidadão. Os resultados dessas ações do Estado são altas taxas de analfabetismo, evasão escolar, exploração sexual, trabalho infantil e exclusão social.

\section{Desenvolvimento}

Analisamos a intervenção das agências internacionais nas políticas educacionais de profusão de valores oferecidos ao Estado brasileiro, com ênfase na investigação das orientações rumo à proteção ao direito à infância presentes nas políticas sociais.

Investigamos documentos oriundos das organizações internacionais, estudos e pesquisas para compreender como tais organizações influenciam as políticas educacionais. Destacamos a Organização das Nações Unidas para a Edu- 
cação, a Ciência e a Cultura (Unesco), Organização Internacional do Trabalho (OIT), o Banco Mundial e o Fundo das Nações Unidas para a Infância (Unicef). São agências independentes, mas ligadas, por conjunção de seus trabalhos, à Organização das Nações Unidas (ONU).

Em 1945, a ONU foi integrada por 51 países, entre eles o Brasil. Na atualidade, conta com mais de 180 países membros, a despeito de o prédio das Nações Unidas localizar-se em Nova York, EUA. As assembleias gerais são instâncias principais da ONU. Têm um caráter deliberativo, representado apenas por países membros. Cada um tem direito apenas a um voto.

Para agir, a ONU depende da boa vontade das grandes potências para evadir um confronto armado.

Em 1963, por exemplo, não conseguiu evitar que os EUA interviessem na Guerra do Vietnã. Depois da Segunda Guerra Mundial, que devastou dezenas de países e tomou a vida de milhares de seres humanos, existia na comunidade internacional um sentimento generalizado de que era necessário encontrar uma forma de manter a paz entre os países (BAILEY, 1963, p. 59).

Da estrutura da ONU fazem parte programas mantidos por escritórios e fundos que laboram para a melhoria das condições econômicas e sociais da população mundial, entre as quais destacamos a população infantil, a que dedicamos nossa pesquisa. A Unesco visa a colaborar na edificação da capacidade humana e institucional na educação, ciências sociais, cultura e comunicação, fomentando ações para o desenvolvimento de professores, o financiamento de projetos às populações carentes desde a década de 1990.

O Banco Mundial também é uma das agências da ONU, inaugurada em $1^{\circ}$ de julho de 1946, por uma conferência com 44 governos participantes em Bretton Woods, New Hampshire, EUA, tendo a incumbência de custear a reconstrução dos países devastados durante a Segunda Guerra Mundial. Para Tommasi (1998), a análise que formula a ação econômica educativa do Banco Mundial é apresentada como resolução para fixar políticas educativas. $\mathrm{O}$ Unicef foi fundado no pós-guerra, sua função é preocupar-se com a educação e a saúde de mães e crianças. A Unesco ampara o patrimônio da humanidade e surgiu na conferência realizada na Inglaterra em 1942. Dedica-se à orientação dos povos a favor do próprio desenvolvimento por meio dos recursos naturais e valores culturais, atua na formação de docentes, conta com estratégias de financiamento e a criação de escolas em regióes afastadas ou de refugiados para a educação básica de qualidade a todos, compromisso firmado na Conferência em Jomtien, Tailândia, 1990. Após 10 anos, muitos países não atingiram o objetivo estabelecido pela comunidade mundial e se reuniram novamente em Dacar, Senegal, em 2000, para reiterar o projeto e proporcionar educação para todos até 2015.

Diante da compreensão dessa situação e constatando, com o passar dos dias, a emergência em dar provimento a ações políticas apropriadas, a ONU constituiu uma comissão para elaboração do Relatório Jacques Delors, o qual aponta ações para a educação do século XXI.

No Brasil, foi traduzido sob o título "Educação: um tesouro a descobrir", e o Ministério da Educação e do Desporto registra ser imprescindível a participação do país neste relatório. O documento representa uma posição ímpar em relação à política educacional de todos os países membros.

A elaboração do "Relatório Jacques Delors" iniciou-se em 1993 e foi concluída em 1996. A comissão de elaboração contou com a participação de especialistas da área de políticas públicas do mundo todo. 
As teses defendidas no relatório, da educação básica à universalidade, voltam-se essencialmente para o desenvolvimento humano entendido como a evolução da capacidade de raciocinar e imaginar, da capacidade de discernir do sentido das responsabilidades (DELORS, 1998, p. 9).

O relatório registra uma compreensão do papel dos professores, retratando que são os agentes de mudança e os formadores de caráter e espírito das próximas gerações, por isso têm de ser libertos de preconceitos étnicos e do totalitarismo, não podendo faltar também o destaque ao papel político, porque são de sua responsabilidade a estabilidade, a reforma e a garantia do sistema educacional. Destacando os quatro pilares básicos e essenciais rumo a um novo conceito de educação: aprender a conhecer, aprender a viver juntos, aprender a fazer $e$ aprender a ser ${ }^{3}$.

A Unesco tem seu escritório no Brasil desde o ano de 1964. É um dos países mais populosos nos quais a Unesco é ativa em ações prioritárias de desenvolvimento no setor da educação. No Brasil há muitos indícios de crianças trabalhando em vez de frequentar a escola. Para combater tal prática foi criado o Bolsa-Escola ${ }^{4}$, que prevê a proteção do futuro dessas crianças, fazendo-as estarem em sala de aula e abdicar do trabalho e de ficar em situação de risco social, variando muito nas regiões brasileiras em que se encontram. A ideia do Bolsa-Escola foi criada e testada a partir de 1995, em Brasília, e se espalhou por outras cidades, inclusive em outros países, como o México, e está em fase de implementação na Bolívia. No total, estima-se que cerca de 20 milhões de crianças são beneficiadas. Entende-se que será um instrumento importante na garantia do direito à infância, considerada a ausência de políticas públicas que atendam a tais carências. No entanto, vale ressaltar que se trata de um serviço social executado por meio de programa.

As seis metas estabelecidas pelo fórum da Educação em Dacar, Senegal, que foram criadas para a melhoria da infraestrutura da educação na infância, garantindo que até 2015 todas as crianças estejam matriculadas nas escolas, melhoria nos índices de erradicação do analfabetismo e melhorias na qualidade da educação. Dos 121 países que participaram do planejamento de metas, apenas 44 cumpriram com o acordo. Antes de o plano de metas para 2015 ser estabelecido, ocorreu uma conferência com as mesmas ideias e o prazo era até o ano $2000^{5}$.

As metas propostas nas declarações dificilmente serão colocadas em prática. As pesquisas na área de políticas públicas e gestão educacional indicam relatórios que descrevem a eficácia dos programas propostos pela Unesco, mas mostram números em vez da qualidade das ações.

No século XXI, 250 milhões de crianças no mundo estão trabalhando. Vivem à margem do atendimento escolar. E essa é a grande questão que buscamos suscitar no artigo, a saber: quais são as orientações da Unesco sobre a educação e suas metas e o que está sendo feito para que possam ser cumpridas?

Em síntese, permanecemos amparados numa assessoria para modificações de nossos sistemas educativos, firmados em uma teoria questionável, mais que isso, a busca produz evidências não conclusivas ou até inversas às próprias hipóteses que conduzem às suas recomendações.

\footnotetext{
${ }^{3}$ GOMES, Candido Alberto. Dos valores proclamados aos valores vividos. Brasília: Unesco, 2001.

${ }^{4}$ Bolsa-Escola - Programa com estratégias mediadoras ao problema de milhões de crianças que trabalham em vez de estudar, propondo incentivos financeiros para as políticas educacionais, efetivando a manutenção e frequência da criança na escola.

${ }^{5}$ Conferência de Jomtien, Tailândia.
} 


\section{Trabalho infantil no Brasil}

Proliferou, no final do século XX e início do século XXI, uma prática cruel no Brasil, o trabalho infantil. Este é um tema, atualmente, discutido ao redor do mundo e, no Brasil, essa temática tem conquistado espaço político, na tentativa de combater o trabalho precoce. $\mathrm{O}$ combate é intencionado por organismos internacionais como a Organização Internacional do Trabalho (OIT), Fundo das Nações Unidas para a Infância (Unicef), Organização das Nações Unidas para a Educação, a Ciência e a Cultura (Unesco), Organização das Nações Unidas (ONU) e Organização Mundial do Comércio (OMC).

O trabalho infantil é uma das formas mais cruéis de exclusão social, compreendendo diversos aspectos que envolvem complexas relações entre as políticas públicas, educação, determinantes socioeconômicos, culturais, pobreza e outros.

No Brasil, há cerca de 3 milhões de crianças trabalhando e este é um dos maiores e principais desafios a serem enfrentados pela nação brasileira. O número alarmante é o resultado do descumprimento dos direitos de todos os cidadãos, sendo alguns: vida digna, liberdade, educação e saúde. Fornecer escolas a todas as crianças é dever do Estado. O caput do art. 227 do texto constitucional dispõe de um amplo conjunto de direitos sobre a educação.

É dever da família, da sociedade e do Estado assegurar à criança $e$ ao adolescente, com absoluta prioridade, o direito à vida, à saúde, à alimentação, à educação, ao lazer, à profissionalização, à cultura, à dignidade, ao respeito, à liberdade e à convivência familiar e comunitária, além de colocá-los a salvo de toda forma de negligência, discriminação, exploração, crueldade e opressão.
O Art. 54 do Estatuto da Criança e do Adolescente diz que:

É dever de o Estado assegurar à criança $e$ ao adolescente:

I - ensino fundamental, obrigatório e gratuito, inclusive para os que a ele não tiveram acesso na idade própria;

II - progressiva extensão da obrigatoriedade e gratuidade ao ensino médio;

IV - atendimento em creche e pré-escola às crianças de zero a seis anos de idade;

V - acesso aos níveis mais elevados do ensino, da pesquisa e da criação artística, segundo a capacidade de cada um;

VI - oferta de ensino noturno regular, adequado às condições do adolescente trabalhador;

VIII - atendimento no ensino fundamental, através de programas suplementares de material didático-escolar, transporte, alimentação e assistência à saúde.

Entendemos que a conquista dos bancos escolares e o acesso à escola é apenas o primeiro passo para que as famílias pobres conquistem a cidadania. Para compreender a ampla temática que estamos discutindo, começaremos abordando quais são os direitos da criança e por que e como esses direitos são desrespeitados.

Declaração dos Direitos Humanos de 10 de dezembro de 1948:

Art. VII - Todos são iguais perante a lei e tem direito, sem qualquer distinção, a igual proteção da lei. Todos têm direito a igual proteção contra qualquer discriminação que viole a presente Declaração e contra qualquer incitamento a tal discriminação. 
Compreende-se que o período mais importante da vida de uma pessoa é a infância. É nesse período que o indivíduo tem as primeiras vivências e experiências de sua vida, como: a linguagem, relações afetivas, reconhecimento de seus sucessos e realizações, encorajamento na realização de atividades como correr e saltar, interação com a natureza e sociedade, amizades, relações com o meio, acesso à cultura, entre outros. As crianças precisam de limites e restrições para se sentir seguras, constituindo as duas ordens formuladas pelos Referenciais Curriculares Nacionais para a Educação Infantil, estabelecendo como principais objetivos a formação pessoal e social e o conhecimento de mundo.

Todo aprendizado ocorre tanto na escola e nas brincadeiras quanto nas famílias. Em consequência a essa necessidade da criança, o Estatuto da Criança e do Adolescente (ECA), garante às crianças o direito à vida, à saúde e à liberdade, o direito de brincar, praticar esportes e divertir-se. A Declaração Universal dos Direitos da Criança assegura às crianças o direito à educação gratuita e ao lazer.

Art. 27. I - Os Estados Partes reconhecem o direito de toda criança a um nível de vida adequado ao seu desenvolvimento físico, mental, espiritual, moral e social.

Os "Referenciais Curriculares Nacionais para a Educação Infantil" orientam que é por meio da educação que são atingidas as competências ou capacidades, considerando as habilidades, interesses e atitudes divergentes de cada criança, afirmando a importância das primeiras experiências vividas na infância.

Embora as crianças desenvolvam suas capacidades de maneira heterogênea, a educação tem por função criar condições para o desenvolvimento integral de todas as crianças, considerando, também as possibilidades de aprendizagem que apresentam nas diferentes faixas etárias. Para que isso ocorra, fazse necessário uma atuação que propicie o desenvolvimento de capacidades envolvendo aquelas de ordem física, afetiva, cognitiva, étnica, estética, de relação interpessoal $e$ inserção social (Referencial Curricular Nacional para a Educação Infantil. Introdução. Volume I. Brasília, MEC/SEF, 1998, p. 47).

As capacidades afirmadas para a educação infantil são as capacidades de ordem física, que são aquelas que se associam com a possibilidade de apropriação e conhecimento das potencialidades corporais, com o autoconhecimento, com o uso do corpo na expressão das emoções.

As capacidades de ordem afetiva são aquelas associadas à construção da autoestima, de atitudes do convívio social, à compreensão de si mesmo e dos outros. As capacidades de ordem cognitiva são aquelas associadas ao desenvolvimento dos recursos para pensar, ao uso e apropriação de formas de representação e comunicação. As capacidades de ordem estética são aquelas associadas à possibilidade de produção artística e apreciação de produções oriundas de diferentes culturas. As capacidades de relação interpessoal e inserção social são aquelas associadas à possibilidade de estabelecer relações de convívio social e de perceber-se como membro participante de uma comunidade com valores próprios. Contudo, segundo o Art. $4^{\circ}$ do ECA:

É dever da família, da comunidade, da sociedade em geral e do Poder Público assegurar, com absoluta prioridade, a efetivação dos direitos referentes à vida, à saúde, à alimentação, à educação, ao esporte, ao lazer, à profissionalização, à cultura, a dignidade, ao respeito, à liberdade e à convivência familiar e comunitária. 
Em muitos lugares do mundo, a criança não brinca e não estuda; ao contrário desse direito, a criança trabalha. Conforme o "Relatório do Desenvolvimento Humano 2000" das Nações Unidas, 100 milhões de crianças vivem ou trabalham nas ruas. No Brasil, há 2,9 milhões de crianças de 5 a 14 anos trabalhando em regime penoso e braçal. Em conformidade com a Pesquisa Nacional por Amostra de Domicílios (PNAD) de 1999, realizada pelo Instituto Brasileiro de Geografia e Estatística (IBGE), as crianças afetadas são de todas as regiões do país. Não são casos isolados, como muitas pessoas pensam, ou seja, são muitas as crianças que estão sendo afastadas de viver uma vida satisfazendo todos ou boa parte dos seus direitos. A infância desses meninos e meninas está presa a atividades penosas ou nocivas para a saúde.

$\mathrm{O}$ direito à vida e à saúde estão assegurados no Art. $7^{\circ}$ do ECA, o qual nos traz:

A criança e o adolescente têm direito a proteção à vida e à saúde, mediante a efetivação de políticas que permitam o nascimento e o desenvolvimento sadio e harmonioso, em condições dignas de existência.

O direito à vida é o direito fundamental e deve ser respeitado porque dele sucedem todos os outros direitos. A Constituição Federal estabeleceu como direitos sociais a saúde, educação, esporte, cultura, lazer, proteção à maternidade e à infância, que serão brevemente descritos a seguir concomitantemente. Ao direito da saúde, a Constituição certifica o atendimento integral a todos os serviços. Nesse âmbito, os municípios devem reunir condições para proporcionar a implementação e a execução da política de atendimento e dos programas de atenção integral. Os responsáveis pela asseguração da saúde são os municípios, mas os poderes públicos estaduais e federais são sempre corresponsáveis na ausência da função municipal (Art. 23, II, CF).
Essa responsabilidade trata da participação. Portanto, ela não exclui o papel da família, da comunidade e dos próprios indivíduos na promoção, proteção e recuperação da saúde.

O Estatuto da Criança e do Adolescente (ECA) prevê os direitos da criança desde a sua concepção. $\mathrm{O}$ direito à vida e à saúde pressupõe o nascimento saudável, atendimento médico desde a gestação, desenvolvimento sadio, políticas públicas que garanta essa proteção em todas as fases de seu desenvolvimento. Os direitos assegurados à gestante (Arts. $8^{\circ}$ e $9^{\circ}, \mathrm{ECA}$ ) são o atendimento pré e perinatal, apoio alimentar, se necessitar, condições do aleitamento materno, inclusive para filhos de mães presas.

A área da saúde é de natureza pública. Conforme a Constituição Federal, a saúde é "um direito de todos e dever do Estado". Cabe ao Poder Público (Arts. 11 e 14 ECA) o atendimento médico à criança e ao adolescente. Do direito à educação, à cultura, ao esporte e ao lazer, o ECA estabelece, no Art. 58:

No processo educacional respeitar-se-ão os valores culturais, artísticos e históricos próprios do contexto social da criança e do adolescente, garantindo-se a estes liberdade de criação e o acesso às fontes de cultura.

Os direitos sociais fundamentais para a criança e para o adolescente têm sido ausentes em muitas localidades do país. De acordo com a ênfase anteriormente citada, a educação deve ser vista como dever do Estado e direito de todos, sendo ricos ou pobres. É esta que habilita a criança, o adolescente, o jovem e o adulto para o pleno desenvolvimento e para o exercício dos seus direitos e a qualificação para o trabalho.

O conceito de educação é extremamente amplo, pois abrange a educação infantil, o ensino fundamental, o ensino médio $e$ ensino técnico e superior, além de incluir 
outras práticas extra-escola, como educativas (esporte, cultura e lazer) [...]. A escola é lugar de criança e adolescente e o trabalho precoce prejudica o desenvolvimento dos mesmos. Com respeito ainda à educação, não há lacunas ou desculpas financeiras suficientes que sustentem a realidade da ausência de vagas na escola $e$ a falta de organização ou estrutura para abrigar dignamente os educandos. Essa responsabilidade cabe ao Poder Público e dele deve ser cobrado (CUSTÓDIO; SILVESTRE, 2004, p. 58).

O direito à educação consiste, nos moldes dos Arts. 53 a 59 do ECA, na igualdade de condições para o acesso e permanência na escola; direito de ser respeitado por seus educadores; direito de contestar os critérios avaliativos, podendo recorrer às instâncias superiores; direito de organização e participação em entidades estudantis; acesso à escola pública e gratuita próxima de sua residência.

A falta de cumprimento de todos os deveres é frequente no Brasil. Em decorrência, uma rede de canal aberta, a Record News, exibiu uma reportagem em 25 de outubro de 2008 informando que 66 milhões de crianças no mundo e 21 milhões no Brasil são consideradas crianças $e$ adolescentes que vivem sem seus direitos. De acordo com a reportagem, a questão que incomoda a sociedade é: as leis brasileiras asseguram e garantem muitos direitos, sim, mas como e com que frequência elas têm sido cumpridas?

A infância está sendo cada vez mais roubada e boa parte dessas crianças, onde estão? Essa questão tão intrigante resulta na maior parte dos 2,9 milhões de crianças brasileiras que estão trabalhando na agricultura, no corte de cana-de-açúcar, na colheita de frutas cítricas, folhas de tabaco, café e uma grande variedade de culturas.

Nas cidades, uma parcela faz "bicos", como lavar carros, vender doces nos semáforos, empacotadores de supermercados, outra parcela trabalha em indústrias, fábricas e nas ruas. Uma parcela considerável sofre os riscos contra sua integridade constantemente, por trabalhar em condições extremamente perigosas e insalubres, como nas carvoarias, manguezais, coleta de lixo e de restos de comida e outros. O trabalhador precoce e os produtos que resultam do seu trabalho beneficiam empresas como siderúrgicas, bancos, montadoras, a maioria de capital estrangeiro e o próprio Governo Federal.

O sistema de produção economicamente desenvolvido retém no setor primário a maioria de nossas crianças e adolescentes, trabalhadores sem escola, sem a proteção da família e do Estado, desempenhando atividades penosas produzindo, não apenas arroz, feijão, açúcar, matéria-prima para carros, laranja para suco, café, pedras, sisal, carvão [...] (CECÍLIO, 2004, p. 27).

Compreendendo os indícios da exploração, perguntamos: com tantas políticas sociais e públicas no Brasil, por que tantas crianças continuam trabalhando em vez de exercerem o direito de estar na escola? Essas crianças e adolescentes não foram abandonados por suas famílias e nem tiveram de se virar sozinhos por quaisquer motivos. A maioria trabalhava juntamente com os pais, ajudando-os em suas atividades, contribuindo para a renda familiar. Muitos podem pensar em como essas famílias são cruéis e que elas poderiam ser indiciadas por violarem as leis estabelecidas e a obrigação que lhes cabe de proporcionar o exercício do direito para que seus filhos possam frequentar a escola. Contudo, para fazer um levantamento de críticas seria necessário que essas mesmas pessoas que formam o chamado "senso comum" conhecessem a realidade dessas famílias, que em sua maioria não vivem, ao menos, com suas necessidades básicas cumpridas por seus salários. 
Esse quadro é muito comum em nosso país. Por exemplo, $20,1 \%$ da população brasileira ${ }^{6}$ ganha menos de um salário mínimo por mês. Para muitas dessas famílias, as necessidades básicas mais urgentes são a alimentação e a habitação. Entre todos esses aspectos, existe a questão da acomodação do trabalhador braçal, justificando a sua falta de esperança na credibilidade do governo no combate aos massacres promovidos nas cadeias produtivas que ocorrem no campo e nas cidades (CECÍLIO, 2004, p. 31).

Acostumadas com a prática, a maioria das crianças e adolescentes que trabalham defendem o trabalho precoce, acreditando que o trabalho educa e gera a disciplina, auxiliando na garantia da sobrevivência de suas famílias. No Brasil, esse ciclo vicioso reporta na pobreza e no trabalho infantil. Os filhos trabalhadores precoces, muitas vezes, não frequentam a escola e, assim, perdem a possibilidade de estudar e futuramente tornar seu trabalho qualificado. Quando essa criança se tornar um adulto, mal saberá ler e escrever. Raras serão as chances de se emancipar politicamente e humanamente. Continuarão trabalhando e mantendo esse ciclo vicioso que sustenta o capital.

A partir do conceito abordado, concretiza-se a ideia de que, no campo e nas periferias das cidades, o trabalho é iniciado antecipadamente. Na consciência dessas crianças e adolescentes, a infância e a adolescência vividas com liberdade, que muitas leis e documentos afirmam como direito, são sonhos impossíveis de serem realizados. Veem o trabalho como uma missão familiar e disciplinadora, justificando que, com o trabalho, não estarão nas ruas praticando atividades criminosas.

A frequência na escola é algo ocasional. O trabalho deixa-os exaustos para estudar. Em consequência, os trabalhadores que chegam aos bancos escolares costumam cursar somente os anos iniciais do ensino fundamental e logo deixam os estudos. Aqueles que persistem nos estudos quase sempre têm baixos rendimentos por causa do cansaço do trabalho. É um fato lastimável com o qual a sociedade brasileira tem convivido. O que nos causa estranhamento é constatar que o governo permanece, mesmo ciente de tantas pesquisas e casos de trabalho infantil, com ações limitadas. O que tem sido feito para evitá-lo? Ou mesmo, por que o Governo ainda insiste em "tampar o sol com a peneira", mostrando números de pesquisas encomendadas para explicar índices de baixa qualidade nas políticas sociais no combate à exploração do trabalho precoce?

Compreendemos que as famílias estão cientes da importância dos estudos, mas, muitas vezes, avaliam que não podem abrir mão de mais um membro da família ajudando no sustento da casa. Nesse impasse, o poder público e empresas privadas têm de desempenhar papéis fundamentais para prover essa carência básica e garantir o acesso de crianças e adolescentes à escola desenvolvendo estratégias que auxiliem as famílias nesse âmbito, fortalecendo a participação da sociedade civil em ações que o Estado deveria desempenhar. O Programa Bolsa-Escola é um exemplo de estratégia acompanhada pela Unesco nessa perspectiva. As ações para erradicação do trabalho infantil são materializadas nas formulações de documentos destinados à proteção da infância e da adolescência. Alguns desses documentos são: Educação para Todos, $\mathrm{NEBAS}^{7}$, relatórios anuais do Unicef, documentos específicos da Unesco, como primeira infância melhor (PIM), entre outros, Organização Internacional do Trabalho (OIT), programas nos quais o Unicef faz parceria com o governo e na maioria das vezes com empresas privadas para a exclusão da taxa de imposto de renda sobre essas empresas.

\footnotetext{
${ }^{6}$ Esta porcentagem da população brasileira representa cerca de 34 milhões de pessoas.

7 Necessidades Básicas de Aprendizagem. 
Para evitar as formas de trabalho penoso no Brasil, foi assinado o "Pacto Bandeirante pela Erradicação do Trabalho Infantil", em abril de 1996, elaborado por órgãos públicos, federações de trabalhadores e empregadores, sindicatos, cooperativas e prefeituras municipais.

Em decorrência dos fatos, os benefícios atribuídos às políticas sociais são permeados por limitações. A perplexidade causada pela ciência dessa realidade nos faz pensar sobre a possibilidade de exercício da cidadania, seja por meio dos programas sociais, seja na garantia de trabalho digno, e traduz em dúvidas sobre a eficácia de ações que são avaliadas na intenção de que constituam políticas de estado.

\section{Considerações finais}

O Estado deve fornecer aos seus cidadãos as condições para uma existência digna, o que deveria ser feito por meio da aplicação dos impostos pagos pela população. O Brasil está longe de desfrutar da cidadania. Estima-se que pelo menos cerca de 21 milhões de crianças e adolescentes não conhecem e não desfrutam de seus direitos. Não há escolas para todos. O salário mínimo não é suficiente para a sobrevivência, o sistema de saúde é deficiente, não há terras para todos ou não são bem distribuídas, autoridades descumprem as leis, muitos políticos e representantes do povo servem a seus próprios interesses. Um imenso quadro de exclusão social e violação dos direitos, entre os quais o direito à infância se desenha.

Por meio da pesquisa, nos apropriamos das orientações legais para a garantia dos direitos das crianças e adolescentes, principalmente, sobre as dificuldades de vivência plena de seus direitos. Como foi abordado na pesquisa, o trabalho infantil e/ou precoce foi e tem sido historicamente formador de diversos tipos de crianças no século XXI. A nossa sociedade con- vive com o trabalho de crianças e adolescentes relacionados, principalmente, com a evasão escolar, analfabetismo e repetência.

\section{REFERÊNCIAS}

BAILEY, Sydney D. A história das Nações Unidas. Rio de Janeiro: Lidador, 1963.

BRASIL. Estatuto da criança e do adolescente. Brasilia: Câmara dos Deputados, Coordenação de Publicações, 2003.

Constituição da República Federativa do Brasil de 1988. Disponível em: <http://www.planalto.gov.br/ ccivil_03/constituicao/constitui\%C3\%A7ao.htm>. Acesso em: $\overline{18} / 3 / 2009$.

. Lei no. 9.394, de 20 de dezembro de 1996. Lei de diretrizes e bases da educação nacional. Disponível em: $<$ http://www.planalto.gov.br/ccivil_03/LEIS/19394.htm>. Acesso em: 18/3/2009.

CECILIO, Maria Aparecida. Laurar e brincar: o trabalho precoce $e$ as conseqüências para o desenvolvimento. Maringá: Massoni, 2004.

DELORS, Jacques. Educação: um tesouro a descobrir. São Paulo: Cortez, MEC: Unesco, 1998.

GOMES, Candido Alberto. Dos valores proclamados aos valores vividos. Brasília: Unesco, 2001.

IRELAND, Timothy. Analfabetismo: até quando? Unesco, 2008. Disponível em: <http://www.brasilia.unesco.org/ noticias/opiniao/artigooutros/analfabetismo-ate-quando $>$. Acesso em: 25/7/2009.

SILVESTRE, Eliana; CUSTÓDIO, Sueli Sampaio Damin. Os direitos infanto-juvenis: pressupostos políticos e jurídicos para a sua concretização. Maringá: Clichetec, 2004.

TOMMASI, Lívia et al. O Banco Mundial e as políticas educacionais. 2. ed. São Paulo: Cortez, 1998.

UNESCO. Declaração mundial sobre educação para todos: satisfação das necessidades básicas de aprendizagem Jomtien, 1990. Brasília: Unesco, 1998.

Unesco, 2006.

VIEIRA, Sofia Lerche. Política educacional no Brasil: introdução histórica. Brasília: Plano, 2003.

Texto aprovado em 18 de novembro de 2010. 